\title{
A contribution to aeromagnetic deculturing in populated areas
}

David Beamish

Geophysical Prospecting, 2017, 65, 292-304

doi: 10.1111/1365-2478.12394

British Geological Survey, Keyworth, Nottingham, NG12 5GG, UK.

dbe@bgs.ac.uk

Corresponding author:

David Beamish

British Geological Survey, Keyworth, Nottingham, NG12 5GG, UK

Email: dbe@bgs.ac.uk

Tel: +44(0)1159363432

Fax: +44(0)1159363437

Keywords: Data processing, noise, magnetics

Running head: aeromagnetic deculturing 


\begin{abstract}
Modern regional airborne magnetic data sets when acquired in populated areas are inevitably degraded by cultural interference. In the UK context, the spatial densities of interfering structures and their complex spatial form severely limit our ability to successfully process and interpret the data. Deculturing procedures previously adopted have used semi-automatic methods that incorporate additional geographical databases that guide a manual assessment and refinement of the acquired database. Here we present an improved component of that procedure that guides the detection of localised responses associated with non-geological perturbations. The procedure derives from a well-established technique for the detection of kimberlite pipes and is a form of moving-window correlation using grid-based data. The procedure lends itself to automatic removal of perturbed data, although manual intervention to accept/reject outputs of the procedure is wise. The technique is evaluated using recently acquired regional UK survey data which benefits from having an offshore component and areas of largely non-magnetic granitic response. The methodology is effective at identifying (and hence removing) the isolated perturbations that form a persistent spatial noise background to the entire data set. Probably in common with all such methods, the technique fails to isolate and remove amalgamated responses due to complex superimposed effects. The procedure forms an improved component of partial-automation in the context of a wider deculturing procedure applied to UK aeromagnetic data.
\end{abstract}




\section{INTRODUCTION}

Cultural noise is a prevalent feature of modern airborne magnetic surveys undertaken in the UK and, by extension, in other densely populated regions. A previous generation of UK aeromagnetic surveys operated at much higher elevations (Beamish and White, 2011) and cultural influences were far less pronounced. A series of recent, less-extensive, surveys has operated using a nominal flight elevation envelope of 56 to $90 \mathrm{~m}$ and a line spacing of $200 \mathrm{~m}$. The lower elevation derives, in part, from a requirement to obtain the best signal-to-noise from additional survey sensors which often include gamma-ray and electromagnetic sensors (Beamish and Young, 2009). These high resolution airborne resource and environmental surveys (HiRES) were established by the British Geological Survey to generate, in part, a modern UK magnetic baseline data set. The surveys have overflown centres of population (towns and cities) at a higher than nominal regulatory height (e.g. $>200 \mathrm{~m}$ ). Many of the non-geological responses (e.g. those due to landfills, waste and spoil zones) are of environmental interest so that discrimination (but not necessarily removal) of such features may be required. The complexities of cultural contributions observed in the UK are comprehensively described and illustrated by Cuss (2003) and Lahti et al. (2007). Magnitudes may typically range from several to several hundred $\mathrm{nT}$. The largest magnitude anomaly (> 80,000 nT) was (ironically) associated with an aluminium smelting works (White and Beamish, 2010)

In all these surveys, the presence and spatial density of cultural interference in the magnetic data initially limits our ability to assess geological responses in a high resolution context. At low survey elevations anomalies resulting from cultural effects have larger amplitudes and a narrower spatial form thus making them more detectable. Cultural magnetic noise suppression and/or removal has been considered in a range of studies. The manual approach is successful but is always more timeconsuming compared with automated techniques (Hassan et al., 1998). More recent schemes consider semi-automatic procedures in which user intervention and decision making plays a part. Nabighian (2005) provides a historical review of deculturing methods. The noise considered usually relates to spatially isolated features in the data (e.g. Muszala et al, 2001) although linear magnetic cultural features have also been studied (Gay, 1986; Gharibi and Pedersen, 2000). In the context of highly sampled modern data, deculturing procedures have moved beyond simple attempts at 'spike' rejection to matching and thus identifying cultural response signatures (e.g. dipolar) within the data set. An example of cross-correlation between a local dipolar anomaly and cultural responses due to oilfield facilities is given by Wilson et al (1997). Schemes for automatic deculturing of magnetic data are often based on the identification and removal of localised equivalent sources (Muszala et al. 2001; Salem et al., 2010). Wavelet decomposition (filtering) methods are described by Leblanc and Morris (2001) and Hassan and Pierce (2005). The former study is more concerned with the noisefloor in aeromagnetic data rather than deculturing per se. The latter study is more relevant here in that it incorporates noise signature identification and removal as part of a wider semi-automated (geographical information and flight-video based) procedure. Both studies note that geological signals will be removed when automatic procedures are adopted. This is inevitable given the amplitude and spectral overlap of geological and cultural signatures present in most data sets. Nabighian (2005) when reviewing methods notes that most methods depend on the recognition of a known anomaly signature and that the anomaly from a town will be an aggregate from many sources, clearly beyond reasonable modelling capabilities. In such cases, it is necessary to resort to manually deleting the culturally-perturbed sections of data. 
Cuss (2003) describes manual techniques that were applied to the HiRES-1 survey of the English East Midlands $(50,000$ line-km). For this survey, the noise content averaged $35 \%$ of the data acquired.

Lahti et al (2006) and Lahti et al (2007) describe a semi-automatic approach to the deculturing of the Northern Ireland (Tellus) survey data (>81,000 line-km). From a total of $13,725,336$ data points, $9 \%$ of the points were removed from the data set. The average length of along-line data removal was $232 \mathrm{~m}$ and the longest was $5 \mathrm{~km}$. In areas of high amplitude and complex spatial gradients (connected with flood basalts) no deculturing was performed.

In survey areas which encompass entirely non-magnetic sedimentary sequences above magnetic basement, it may be possible to provide a simplified and adequate deculturing procedure based on the amplitude of the analytic signal (AS) as described by White and Beamish (2011). However in the general case, we continue to assert that in order to provide UK magnetic data that is fit-for-purpose for general users of the data, a semi-automatic procedure is required.

A significant component of the procedure involves the assembly of reference digital material (e.g. $1: 25 \mathrm{k}, 1: 50 \mathrm{k}$ topographic maps, 1:50k bedrock geology maps) within a GIS. We note that with the introduction of high-quality, georeferenced air photography, downward-looking video/stills, may no longer be a survey acquisition requirement. Lahti et al (2006) and Lahti et al (2007) describe the use of a postcode database that identifies all properties capable of receiving mail. The principal was to give each postcode location an area of influence (e.g. a radius of $125 \mathrm{~m}$ ) and potentially remove the along-line magnetic data from that area. The 'removal' actually took place in an additional masking channel of the survey database. Since the limitations of this approach are self-evident, a second lengthy stage of manual refining then took place based on the postcode procedure, the assembled GIS materials and the behaviour of the magnetic data. Verification or rejection of the postcode procedure took place and cultural class types (house, road, power-line, pylon/mast, railway, populated site, moving object) were identified and coded alongside the masking channel.

Here we consider an alternative procedure for identifying localised anomalies that allows sections of data influenced by local anomalies to be identified and potentially excised from the magnetic database. The cultural anomaly removal can thus take place automatically or can include a degree of manual intervention. The method considered is a well-established technique for identifying magnetic anomalies associated with kimberlite pipes (Keating, 1995; Keating and Sailhac, 2004). The procedure is a form of equivalent-source assessment and is grid-based. Developed as a movingwindow correlation technique, the procedure avoids heavy computational overheads and is simple to apply. Although the identification procedure is grid-based, data removal takes place along line sections of the magnetic database prior to interpolation of the excised data and subsequent regridding.

\section{AIRBORNE DATA AND GEOLOGIC CONTEXT}

The locations of recent high resolution, multi-parameter geophysical surveys in the UK are shown by Beamish and White (2014). Here we consider data from the SW area of England identified in Figure 1. The majority of the survey, referred to as TellusSW, was flown in the latter half of 2013. The wider geoscientific TellusSW project is described at http://www.tellusgb.ac.uk/home.html.

The 61,000 line-km of airborne geophysical data and the processing undertaken are described by Beamish and White (2014). The survey used a N-S line separation of $200 \mathrm{~m}$ and a magnetic data 
sampling of $20 \mathrm{~Hz}$ providing a mean along-line sampling of $3.6 \mathrm{~m}$. The survey achieved a mean flying elevation of $92 \mathrm{~m}$ from a nominal elevation of $79 \mathrm{~m}$. The main onshore survey includes an offshore ribbon extension.

The total field magnetic anomaly (TMI) data from the survey are shown as an equal-colour area image in Figure 1a. Here we use reduced-to-pole magnetic data (TMI-RTP) unless otherwise stated. Grids are based on a $40 \mathrm{~m}$ cell size. At the scale shown, the main features in the magnetic data comprise a strong magnetic anomaly separating Devonian sediments to the SW from Carboniferous strata to the NE. To the north of this feature a large scale positive magnetic feature associated with the Carboniferous Culm Basin is present. The anomaly appears to drape around the northern edges of two granite outcrops which are part of a wider scale set of outcrops (labelled in Fig. 1a) associated with an underlying granite batholith. The granites have a low magnetic susceptibility, typically < $0.25 .10^{-3} \mathrm{SI}$, and as can be seen in Figure $1 \mathrm{a}$, only regional gradients are observed across the outcrop locations.

The Cornubian batholith intruded existing country rocks towards the close of the Variscan Orogeny (late Carboniferous to Permian). The granite exposures are surrounded by contact-metamorphosed aureoles. Hydrothermal fluids operated to allow deposition of metallic elements (tin-tungsten and copper-lead-zinc-iron-arsenic). The centuries-old mining of ores across the region has provided a wealth of detailed information on the nature of the deposits (Dines, 1956).

The low gradient areas of the TMI-RTP data reveal a high density of localised perturbations that are shown in more detail across Area A (the Land's End granite) in Figure 1b. Within this area we have chosen 2 sub-areas labelled $B(1.6 \times 1.6 \mathrm{~km})$ and $C(10 \times 10 \mathrm{~km})$, within which we assess the deculturing procedures. The largely non-magnetic character of the granite outcrop and the far more complex character of the magnetic aureole surrounding the granite is evident in Figure $1 \mathrm{~b}$.

\section{METHODOLOGY}

Following the work of Keating (1995), Keating and Sailhac (2004) discuss methods to identify magnetic anomalies associated with kimberlite pipes. They note that for a vertical cylinder, the shape of the analytic signal (AS) of the magnetic field is nearly independent of field orientation and remanence and always results in a compact, almost circular anomaly. The authors then present a simple pattern recognition technique, based on a regression over a moving window, between the AS of the observed magnetic field and the theoretical AS of a magnetic vertical cylinder. The authors conclude that the procedure is an effective tool to identify potential targets.

Keating and Sailhac (2004) provide theoretical studies of the influence of magnetic field orientation and the influence of the radius and size of the cylinder model. These studies form the basis of the application of the same technique to identify and locate sources of cultural interference from compact bodies, considered here. The persistent spatial form of interference from individual structures (e.g. farms) across the rural landscape is similarly compact and circular in form. The technique is only applicable to such isolated perturbations and where multiple structures provide an amalgamated response, equivalent detection is not possible due to both the modified shape and extent of the perturbation. 
Ideally we would like to discriminate cultural and geological sources. As is readily demonstrated using offshore data, the pattern-recognition technique, although focussed on compact circular perturbations, will also isolate portions of geological signals, particularly those associated with turning points (e.g. maxima). Manual intervention is required to exclude these occurrences. Although kimberlite pipes are not an exploration target for UK data sets, some instances of volcanic plugs, in specific geological settings, could be assessed. No known instances of such structures exist in the data set considered here.

Keating and Sailhac (2004) discuss model cylinder parameters used for the application of the technique in 3 different surveys. The average inclination and declination for the current survey are $65.54^{\circ} \mathrm{n}$ and $-2.54^{\circ}$, respectively and the typical sensor height is 80 to $90 \mathrm{~m}$. Cultural perturbations are persistently dipolar with a negative excursion to the north and a positive excursion to the south. Clearly the parameters of the cylinder model are a function of the survey parameters and the geological, or in this case, cultural, parameters encountered.

From flight-lines at $200 \mathrm{~m}$ intervals, a grid cell size of $40 \mathrm{~m}$ is used in this analysis. Following experimentation we have used an at-surface top to the cylinder with a radius of $100 \mathrm{~m}$. An infinite cylinder is employed. The response of the cylinder is then calculated at the survey height. The response is defined digitally using 9x9 grid cells giving a rectangular scale length of $320 \mathrm{~m}$. The number of cells employed is user-defined. This length scale defines a window that is used for a correlation procedure based on moving the window across the data grid.

The procedure uses a simple linear regression between the model cylinder response and the data and provides a correlation coefficient, a standard error of fit together with the slope and the intercept of the regression fit. We have examined the cylinder response in terms of both the TMIRTP response and the AS response derived from the TMI field. The standard form of the resulting control windows used here are shown in Figure 2. Amplitudes are arbitrary and not critical to the correlation analysis. When applied to the observations the AS response is again derived from the TMI (non-RTP) field. The moving window procedure inevitably provides a cluster of points in the vicinity of a target response. The results are used to screen for potential targets. In practice, one first retains solutions that have a correlation greater than, say, $70 \%$ to $75 \%$ and a relative error of typically less than $10 \%$. Here we refer to the existing ensemble of procedures described above as the KS methodology.

\section{Application}

The solutions obtained are point locations, which as discussed later, form clusters of between 1 and say 8 points, separated by the grid cell interval of $40 \mathrm{~m}$. Within a given area, all solutions can be accepted or manual intervention can be applied to remove one or more clusters that are deemed non-cultural. Existing procedures for deculturing are based on the removal of the identified nongeologically perturbed section of line-data. Sections of line-data are therefore excised from the survey database leaving data gaps. This procedure can be undertaken manually but the KS methodology lends itself to automation.

Within a GIS environment each KS solution point can be buffered with a specific radius to provide a circle of specific areal extent. The actual radius used will be partially a function of the survey line separation and the lateral scale of along-line perturbations. It is then possible to spatially join the 
TMI point data with a database of the buffered solutions. The TMI point data that fall within each buffered solution can then be erased to effectively generate TMI line data with data gaps controlled by the KS point solutions obtained. In practice we have found it preferable to retain the full cluster of solutions (above a defined threshold) in the procedure. The radius to be used is a matter of experimentation. For our $200 \mathrm{~m}$ line separations we have considered buffer radial values of between 100 and $200 \mathrm{~m}$. Correlations can be either positive or negative with the latter being generated by a reversely magnetised body. For the purposes of identification of cultural perturbations we use only positive correlations.

Given a revised TMI database with along-line data gaps it is necessary to reconstruct data values across the gaps. The two common methods used are (i) along-line interpolation and (ii) grid-based reconstruction of the along-line data. In cases where data gaps are long, along-line interpolation may give rise to discontinuous behaviour. The two methods were extensively compared, for UK data sets, by Cuss (2003). It was found that the best grid-format results were achieved by gridding the line-data with gaps (no interpolation applied) since the gridding algorithm (minimum curvature) is able to reconstruct the 2D nature of the potential field surface. This approach was further adopted in the large Northern Ireland (Tellus) magnetic data set by Lahti et al. (2007) and is again adopted here.

\section{RESULTS}

\section{Study Area 1}

In order to demonstrate the detailed cultural responses typically observed, we consider the $1.6 \times 1.6$ $\mathrm{km}$ rectangle labelled ' $\mathrm{C}$ ' in Figure $1 \mathrm{~b}$. The rural area is centrally located on the Land's End granite outcrop and defines an area apparently devoid of magnetic gradients due to geology. The mean survey elevation across the study area was $88 \mathrm{~m}$. Figure 3a shows the N-S flight lines on a background 1:50k topographic map. Locations obtained from the postcode database are shown with red symbols and it is evident that a sparse distribution of farms defines the main potential for cultural interference. Figure $3 \mathrm{~b}$ shows an equal-area colour image of the TMI-RTP data gridded with a cell size of $40 \mathrm{~m}$. The data range is $8.06 \mathrm{nT}$ and the flight lines and postcode locations are shown in white. It is evident that the farms, many with multiple postcodes, are associated with localised positive features in the TMI-RTP data. The working hypothesis is therefore that the majority of perturbations are generated by cultural interference. The along-line data ( $3 \mathrm{~m}$ sampling) for one flight line (arrowed) is considered next.

The TMI-RTP data (with local mean removed) along the $1.6 \mathrm{~km} \mathrm{~N}-\mathrm{S}$ traverse is shown in Figure 4. The lower panel shows a rotated portion of the image of Figure 3a used to identify the location and extent of the farm structures. The TMI-RTP data display a series of 3 dipolar excursions with a maximum peak-to-peak range of $9 \mathrm{nT}$. The lateral scale of the perturbations is estimated to be in the range from 400 to $500 \mathrm{~m}$. When considering the along-line removal of such perturbations, it is obvious that the residual (non-perturbed) background level is difficult to establish given the potential for overlap across sequential excursions. The along-line AS calculated from a grid of TMI values is also shown in Figure 3a. The 'shoulders' in the AS response are the result of curvature in the $x$ and $y$ derivative TMI grids. Peak values in the AS response are consistent with positive peaks in 
the TMI-RTP data and lateral scales of the AS behaviour are also similar to those of the TMI-RTP data.

The results of applying the KS methodology to both the TMI-RTP data and the AS data are shown in Figures $5 a$ and $5 b$, respectively. The solutions displayed are for positive correlations above $70 \%$ and for standard errors below $10 \%$. The solution clusters typically display a central maximum in the correlation coefficient that decays to lower values around the perimeter. Each solution within a cluster is necessarily separated by $40 \mathrm{~m}$. The TMI-RTP solutions (Fig. 5a) can be compared with the data shown in Figure $3 \mathrm{~b}$. Figure $5 \mathrm{~b}$ shows the corresponding solutions obtained using the AS grid. Contour lines indicate the behaviour of the AS data above a value of $0.02 \mathrm{nT} / \mathrm{m}$. For the most part, the 2 sets of solutions provide equivalent detection in association with locations in the vicinity of the farms. Two clusters (labelled A and B in Figure. 5a) are however absent in Figure 5b. Closer inspection indicates that locations $A$ and $B$ are not associated with structures on the ground. In the UK, it is never possible to rule-out concealed former land-use materials that produce localised perturbations. Generally however we have found the AS response is more suited to the robust identification of cultural responses using the KS methodology. In this first example we infer that all the spatial variations observed are due to cultural influences and we now consider a larger data set that displays both geological and cultural responses.

\section{Study Area 2}

The second case-study area is a $10 \times 10 \mathrm{~km}$ rectangle labelled ' $\mathrm{B}$ ' in Figure $1 \mathrm{~b}$. A location map is shown in Figure 6a. The area is located on the edge of the granite outcrop and extends offshore where cultural interference is expected to be less extensive than onshore (i.e. apart from sea-bed wrecks). The area should allow an assessment of the procedure applied to largely non-cultural (entirely geological) sources. The mean survey altitude across the area was $92 \mathrm{~m}$. The granite in the vicinity of St. Just (Fig. 6a) is a well-known tin-mining centre comprehensively described by Dines (1956). Knowledge obtained from the mines has enabled a set of inferred mineral lodes to be mapped as shown in Figure $6 \mathrm{~b}$ in relation to the bedrock geology. Dines (1956) describes a coastal 'emanative centre' associated with the tin lodes, some of which were mined below the sea-bed. The magnetic information for the area suggests that the postulated centre is associated with an extensive offshore magnetic centre with a maximum intensity close to the contact of granite and metamorphosed 'Killas' country rock (Fig. 6c).

The AS of the TMI data is shown in Figure $6 \mathrm{c}$ using an equal-area colour scheme. The KS methodology applied to these data produced the set of clustered solutions shown as white dots in Figure $6 \mathrm{c}$. Standard parameters were used and clusters of solutions with a correlation coefficient > $70 \%$ are shown. The solutions necessarily locate isolated peaks in the AS response and these occur both on- and off-shore. In the active magnetic gradient area offshore, solutions are associated with isolated peaks which are assumed geological. Onshore, the solutions may be considered in relation to geographic mapping information (typically at 1:50k or 1:25k scale) as discussed previously. The majority of solution clusters shown in Figure $6 \mathrm{c}$ are related to dwellings and agricultural features however some solutions are associated with open ground. These latter features, defined as a localised AS response, are not considered geological in origin and are incorporated in the deculturing procedure (their source is uncertain). It is possible, at this stage, to provide manual intervention and discard 'open-ground' responses from the KS solution database. 
Conurbations such as the town of St. Just (population 4,637) tend to produce amalgamated cultural magnetic responses. Survey elevation is also greater above such features. Only two solutions are detected although the zone of perturbation in the AS response is spatially much larger. The method therefore simply subdues the conurbation response. Conurbations are well-defined as spatial polygons in other geographical databases (see Figure 7a) and so their non-geological responses can be isolated and removed by additional automated exclusion procedures, if required.

For a survey with a coastal ribbon component, such as that considered here, it is possible to remove (exclude) the offshore spatial domain from the procedure. The exclusion is a user-defined choice and may be based on the spatial density of large tonnage, off-shore wrecks. The responses from such wrecks are typically more difficult to identify as truly 'cultural' unless an appropriate and accurate marine databases exists. This broad-scale exclusion is carried out here and ensures only onshore responses from the KS procedure are assessed. The result of excluding the identified clusters (Fig. $6 c)$ from the line data using a buffer radius of $200 \mathrm{~m}$ is shown in Figure $6 \mathrm{~d}$. The diameter of $400 \mathrm{~m}$ used here is consistent, although slightly low, in relation to the along-line behaviour of individual farms shown in Figure 4. It is evident that individual clusters may generate data gaps across two, or more, lines. Sequences of clusters then form spatially-persistent gaps, trending across survey lines, in the data set.

As noted previously, the preferred method of data set recovery is to regrid the decultured data (containing gaps) using a minimum curvature algorithm. The same original cell-size $(40 \mathrm{~m})$ is maintained. The result of regridding often requires a final stage of micro-levelling and this has been applied here. Figure 7a shows the original TMI-RTP data set using an equal-area colour histogram. Superimposed, for reference, are a series of polygons from a database defining small urban areas (clusters of dwellings and buildings). The decultured data set is compared in equivalent form in Figure $7 \mathrm{~b}$. It is evident that the decultured data set still retains a significant amount of localised, nongeological perturbations. Some of these are identified as A (a conurbation), B and C (a conurbation), together with the conurbation of St. Just. These larger amplitude responses are partially retained due to their more complex shapes (due to amalgamated responses). Despite this limitation at the local scale, the procedure does provide a revised TMI data set with more geologically plausible gradients particularly at the larger scale.

Although the offshore zone may be excluded from the procedure, active gradient areas such those observed offshore in Figures 6 and 7 will also be modified by the KS procedure when they occur onshore. To evaluate such effects we now consider the $4 \times 4 \mathrm{~km}$ offshore area in the NW of the study area shown by the square in Figures $6 c$ and $6 d$. The TMI data across the area is shown using an equal-area colour histogram image in Figure 8a. The KS solution clusters (from the AS image in Figure $6 \mathrm{c}$ ) are shown with white symbols. It can be seen that solutions are obtained in areas of both high and low gradient. There is a tendency for a reduced number of solutions, within a cluster, in the lower gradient areas. Since there are many hundreds of wrecks off the coast of SW England (although not all metallic) it is impossible to rule out responses from the sea-bed. The water depth across the area is $50 \mathrm{~m}$ or less. Wreck detection is more commonly the subject of marine geophysical surveying. Formulae given by English Heritage (2013) suggest the response from a 10 ton, or greater, vessel should be detectable across the area at the nominal altitude of the present survey. Anomalies associated with solution clusters at locations $A$ and $B$ are dipolar with the correct polarity that might be associated with such occurrences. The deculturing procedure, previously described, when 
applied to the offshore area produced the equivalent image shown in Figure $8 \mathrm{~b}$. The low gradient area in the west and north is largely unmodified. Anomalies at locations A and B have clearly been excised. Elsewhere the peak intensities are largely unmodified and the anomaly shape modification that takes place is a result of data removal at low amplitude locations.

The above analyses describe the general applicability and limitations of the technique applied to the data set. Since the technique is spatially focused, large amplitude and more extensive cultural influences remain in the data set. These have been referred to previously as amalgamated responses and form the basis for the third study area.

\section{Study Area 3}

A $2 \times 2 \mathrm{~km}$ study area on the Dartmoor (largely non-magnetic) granite is shown arrowed in Figure $1 \mathrm{a}$. The rectangle is centred on an isolated village containing Dartmoor prison adjacent and to the north of the village as shown in Figure 9a. Also shown on the image are postcode locations (red symbols). It can be noted that several outlying locations (e.g. the farm in the NE) do not have associated postcode locations. The along-line TMI magnetic data across the area are shown as positive-negative wiggle-trace variations which identify a series of small and large amplitude perturbations in the immediate vicinity of the village and prison. These are interpreted as entirely cultural with the maximum excursions being several tens of $\mathrm{nT}$ in magnitude. Beyond the village a series of more localised perturbations are observed. The KS solution clusters are also shown and identify only 3 localities within the village/prison area. Elsewhere, seven clusters are observed with two of the locations associated with open ground (correlation $<80 \%$ ). The contour lines indicate TMI-AS values $>0.03 \mathrm{nT} / \mathrm{m}$ and are used to reference the TMI-AS behaviour also shown as contours in Figures $9 \mathrm{c}, \mathrm{d}$.

Figure 9c shows an equal-area colour plot of the TMI-RTP data which amplifies and consolidates (in a grid sense) the general characteristics observed in TMI data shown in Figure 9b. The village-prison anomaly is spatially extensive and outliers in the TMI-AS response (e.g. values $>0.03 \mathrm{nT} / \mathrm{m}$ ) are associated with the KS solution clusters shown in Figure $9 \mathrm{~b}$. The deculturing procedure applied to these data produced the image shown in Figure $9 \mathrm{~d}$. It is evident that the outlier perturbations have been adequately excised leaving the central amalgamated response although the peak amplitude has been reduced from 55 to $5 \mathrm{nT} / \mathrm{m}$.

Apart from a regional geological gradient tracking approximately N-S across the $2 \times 2 \mathrm{~km}$ area, we regard the majority of perturbations observed to be cultural in origin. They are broadly defined by the TMI-AS response contours with values $>0.03 \mathrm{nT} / \mathrm{m}$. Successful removal at non-village-prison localities is largely achieved by the automatic application of the KS methodology, as shown in Figure $9 \mathrm{~d}$. The amalgamated response across the village-prison area is largely retained. The polygons shown in Figure 9d are from a database defining small urban areas and it is evident that the use of such information, although assisting, would not provide a basis for the automatic removal of the perturbations present.

\section{DISCUSSION}

We have considered the adaptation of an existing (KS) methodology for the detection of kimberlite pipes for the identification, and subsequent removal, of isolated cultural features contained in modern high resolution UK aeromagnetic data. The technique incorporates both equivalent source 
and grid-parameter spatial adjustments that enable a tuning of the procedure to particular surveyspecific requirements. The KS methodology provides a spatial database of clustered solutions that also incorporate correlation and error assessments which allow a further degree of tuning. The solutions can be readily assessed using additional geographical information and accepted or rejected.

The KS methodology applied to the TMI-AS data is effective at identifying (and automatically removing) the isolated perturbations, largely from rural locations, that form a persistent spatial noise background. The spatial density and amplitude of such background perturbations severely hamper the detection of more subtle geological gradients within the data set.

The limitations of the methodology are that localised perturbations deriving from geological features are also identified. When automatic procedures are applied in a deculturing procedure, it is inevitable that geological signal will also be removed. This is due to amplitude and spectral overlap between the 2 types of response. The KS methodology identifies only spatially localised features. It has been demonstrated that these are typically associated with peaks in larger-scale TMI-AS geological responses. Although for our data the offshore data domain can be excluded from the KS solution database, onshore data must be manually examined or the limited modifications to the geological signal accepted.

The main limitation of the procedure lies in the partial identification of spatially amalgamated responses. Such features are generally complex (they are observed in all shapes and sizes). In the conurbation case (towns and urban) the limitations of using geographical database polygons to isolate (and remove) potential influences has been demonstrated. Although such responses may be attenuated by the procedure, user intervention is required to fully isolate these responses and manually remove the associated line-data. The KS procedure further assists in this regard.

\section{ACKNOWLEDGMENTS}

My thanks go to Maurizo Fedi and an anonymous reviewer for their assistance with the review process. Topographic map data based upon Ordnance Survey data with the permission of the Controller of Her Majesty's Stationery Office, (C) Crown copyright. This paper is published with the permission of the Executive Director, British Geological Survey (NERC).

\section{REFERENCES}

Beamish, D. and White, J.C. 2011. Aeromagnetic data in the UK: a study of the information content of baseline and modern surveys across Anglesey, North Wales. Geophysical Journal International 184, 171-190.

Beamish, D. and Young, M. 2009. The geophysics of Northern Island: the Tellus effect. First Break 27, 43-49.

Beamish, D. and White, J. 2014. TellusSW : airborne geophysical data and processing report. British Geological Survey Open Report, OR/14/014. 
Cuss, R.J. 2003. The removal of cultural noise from high-resolution aeromagnetic data acquired over highly developed areas; manual approaches to data cleansing from the HiRES-1 survey. First Break 21, 12-18.

Dines, H.G. 1956. The metalliferous mining region of south-west England. Memoir of the Geological Survey of Great Britain, HMSO, London.

English Heritage, 2013. Marine Geophysics data acquisition, processing and interpretation, Guidance notes. http://www.english-heritage.org.uk/publications/marine-geophysics-dataacquisitionprocessing-interpretation/

Keating, P. 1995. A simple technique to identify magnetic anomalies due to kimberlite pipes. Exploration and Mining Geology 4, 121-125.

Keating, P. and Sailhac, P. 2004. Use of the analytic signal to identify magnetic anomalies due to kimberlite pipes. Geophysics 69, 180-190.

Lahti, M., Beamish, D., Cuss, R.J., and Williams, J. 2007. Deculturing of the Northern Ireland Tellus magnetic data. British Geological Survey Technical Report, IR/07/147.

Leblanc, G.E. and Morris, W.A. 2001. Denoising of aeromagnetic data via the wavelet transform. Geophysics 66, 1793-1864.

Lee, M.K., Peart, R.J., Jones, D.G., Beamish, D., and Vironmaki, J. 2001. Applications and challenges for high resolution airborne surveys in populated areas. EAGE 63rd Conference, Amsterdam, The Netherlands, Extended Abstracts, Paper IA-1.

Nabighian, M. N., Grauch, V. J. S., Hansen, R. O., LaFehr, T. R., Li, Y., Peirce, J. W., Phillips, J. D. and Ruder, M. E. 2005, The historical development of the magnetic method in exploration. Geophysics 70, 33-61

Muszala, S., Stoffa, P. L.and Lawver, L. A. 2001. An application for removing cultural noise from aeromagnetic data. Geophysics 66, 213-219.

Gay, S.P. Jr. 1986. The effects of cathodically protected pipelines on aeromagnetic surveys. Geophysics 51, 973-976.

Gharibi, M. and Pedersen, L. P. 2000. Removal of DC power line magnetic field effects from airborne total magnetic field measurements. Geophysical Prospecting 48, 617-628.

Hassan, H. H., Peirce, J. W., Pearson, W.C. and Pearson, M.J. 1998. Cultural editing of HRAM data: Comparison of techniques. Canadian Journal of Exploration Geophysics 34, 16-22.

Hassan, H.H. and Peirce, J. W. 2005. SAUCE: a new technique to remove cultural noise from HRAM data. The Leading Edge 24, 246-250.

Salem A., Lei K.X., Green, C., Fairhead, J.D. and Stanley, G. 2010. Removal of cultural noise from high-resolution aeromagnetic data using a two stage equivalent source approach. Exploration Geophysics 41, 163-169. 
White, J.C. and Beamish, D. 2010. The HiRES airborne geophysical survey of Anglesey: processing report. British Geological Survey Open Report, OR/10/002.

White, J.C. and Beamish, D. 2011. Magnetic structural information obtained from the HiRES airborne survey of the Isle of Wight. Proceedings of the Geologists' Association 122, 781-786.

Wilson, C.R. 1997. A high precision aeromagnetic survey near the Glen Hummel Field in Texas; Identification of cultural and sedimentary sources. The Leading Edge 16, 37-42. 
FIGURES
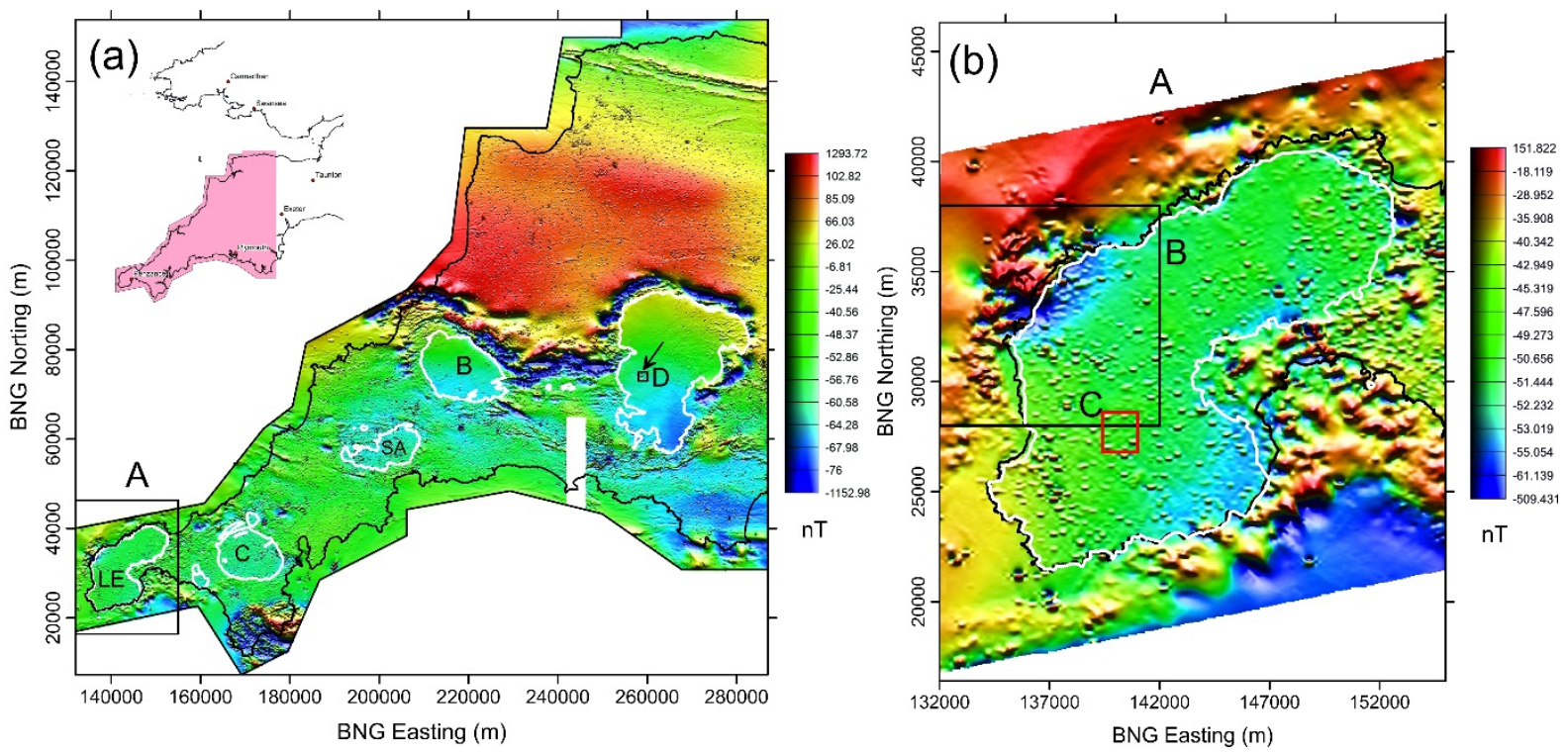

Figure 1. Location maps and magnetic data. (a) Tellus SW survey area (inset) and equal-area colour image of TMI-RTP data. Granite outcrops are identified as D (Dartmoor), B (Bodmin), SA (St. Austell), $C$ (Carnmenellis) and LE (Land's End). Rectangle A is shown expanded in (b). Arrowed rectangle is one of 3 study areas. (b) Equal area colour image of TMI-RTP data across Area A with two study areas identified as B and C. BNG refers to British National Grid.
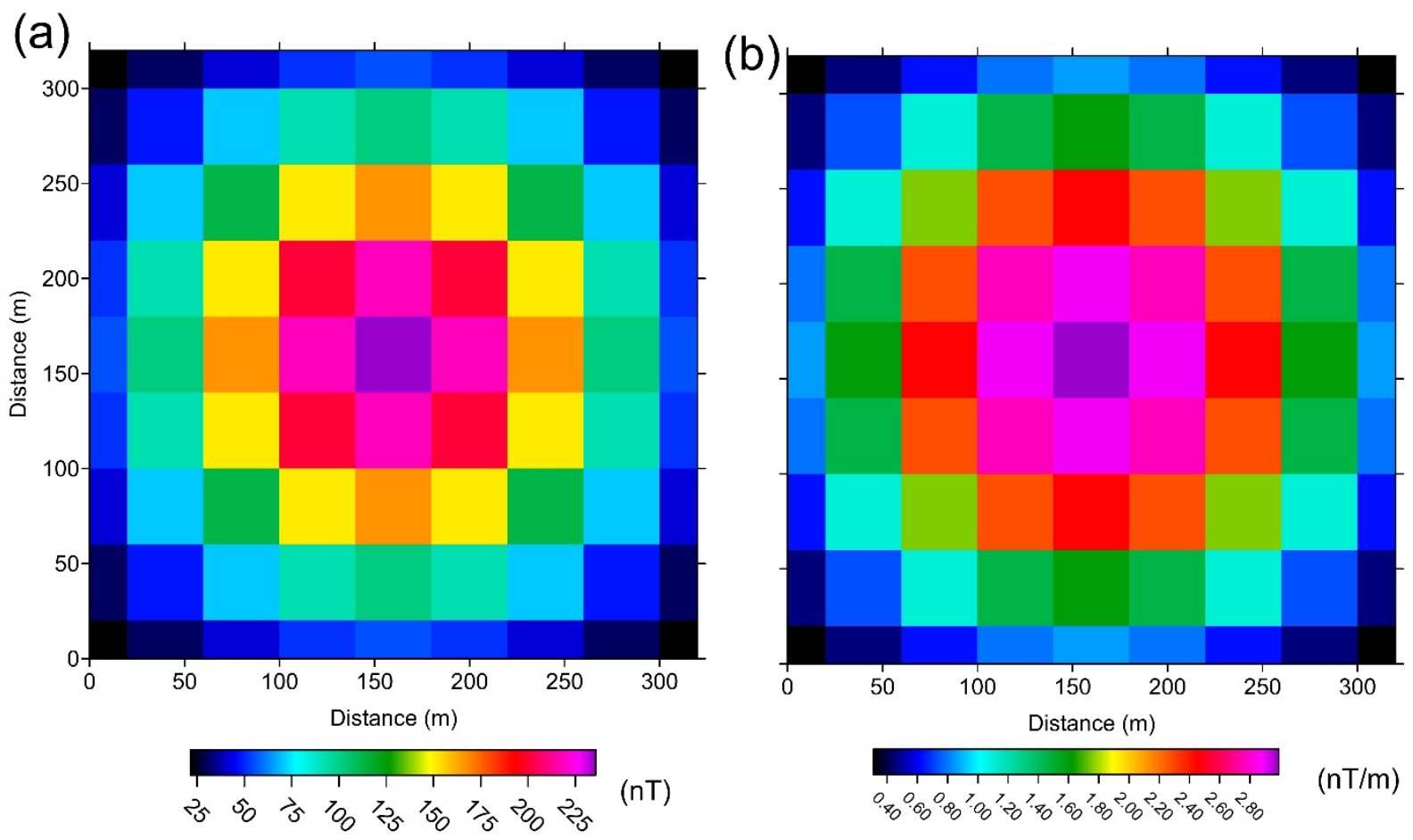

Figure 2. Images of the magnetic grid response of an at-surface cylinder (infinite depth) using a magnetisation scale factor of 100 , at a height of $80 \mathrm{~m}$. The magnetic parameters are $65.5^{\circ}$ (Inclination), $-2.7^{\circ}$ (Declination). The grid cell size is $40 \mathrm{~m}$ and $9 \times 9$ grid cells are used. (a) TMI-RTP. (b) TMI-AS (Analytic Signal). 

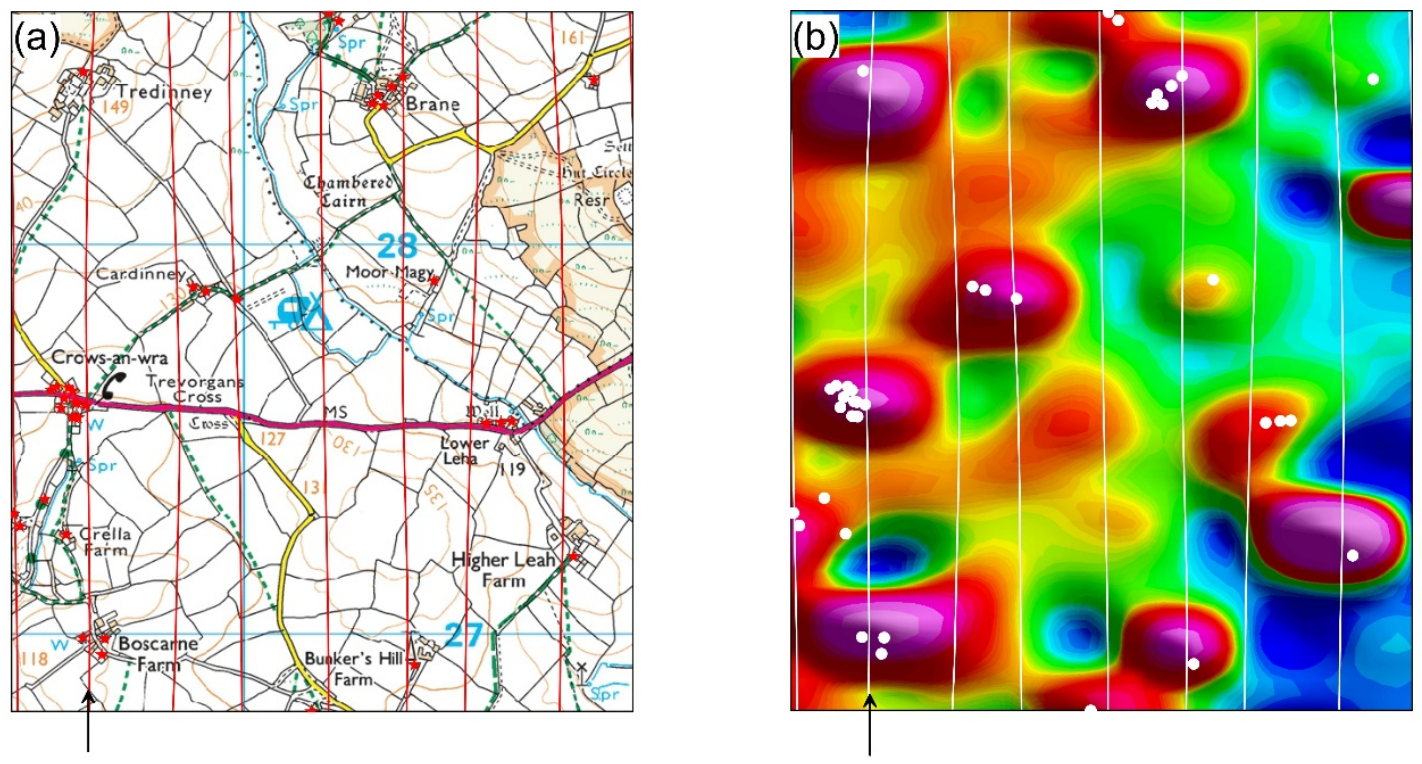

Figure 3. Study Area 1, $1.6 \times 1.6 \mathrm{~km}$. (a) Background 1:25k OS map with N-S flight lines, postcode symbols in red. (b) Equal-area colour image of TMI-RTP data with N-S flight lines and postcode symbols in white. Arrowed line is used in Figure 4. 




Figure 4. Study Area 1. The TMI-RTP and TMI-AS data along a selected flight line, from South to North. The lower panel shows a rotated view of the flight line (in red) and background map. 

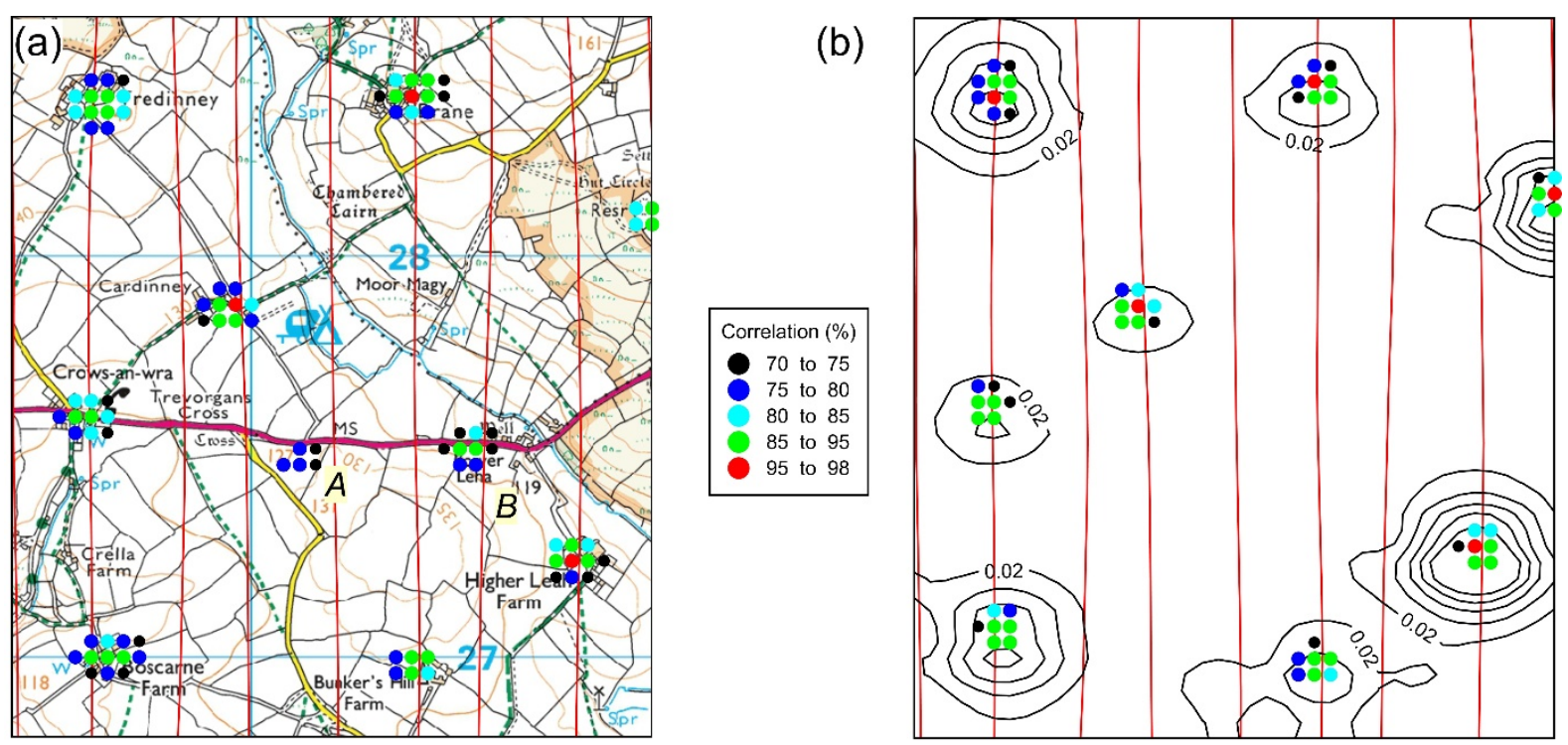

Figure 5. Study Area 1, $1.6 \times 1.6 \mathrm{~km}$. (a) Background 1:25k OS map with N-S flight lines and colourcoded KS solutions with correlation coefficients $>70 \%$, obtained using the TMI-RTP data. (b) Colourcoded KS solutions with correlation coefficients $>70 \%$, obtained using the TMI-AS data. Contours show TMI-AS values $>0.02 \mathrm{nT} / \mathrm{m}$, contour interval $0.02 \mathrm{nT} / \mathrm{m}$. 


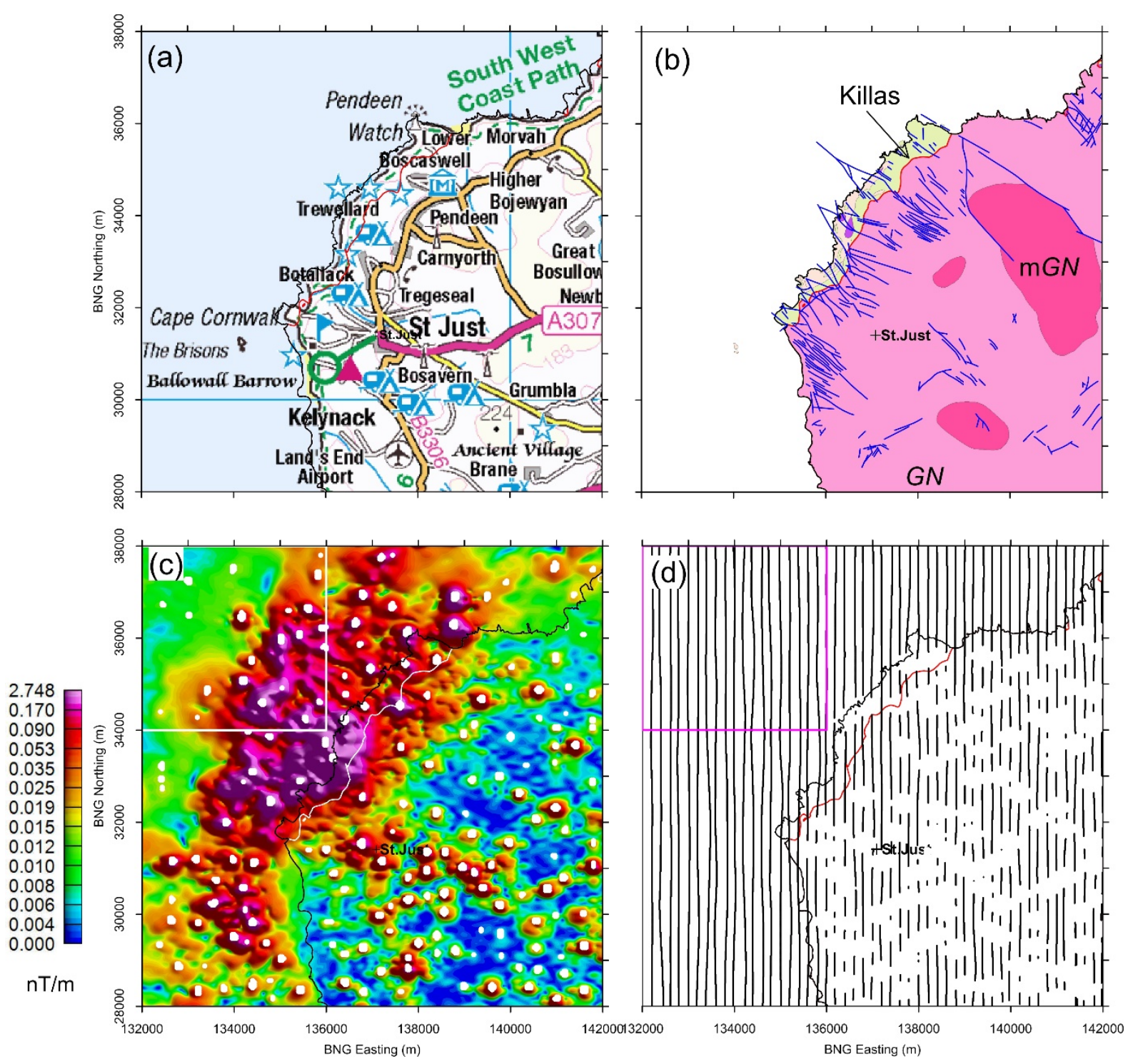

Figure 6. Study Area 2, $10 \times 10$ km. (a) Reference 1:250k OS map. (b) 1:50 Bedrock geology.

$\mathrm{GN}=$ Granite, $\mathrm{mGN}=$ microgranite (aplitic), Killas= slate and siltstone. Blue lines are inferred mineral veins. Granite contact is repeated in subsequent images. (c) TMI-AS equal-area colour image with KS solution clusters as white symbols. (d) N-S flight lines with onshore data gaps produced by automatic removal of solution clusters shown in (c). NW $4 \times 4$ km rectangle area is used in Figure 8. 

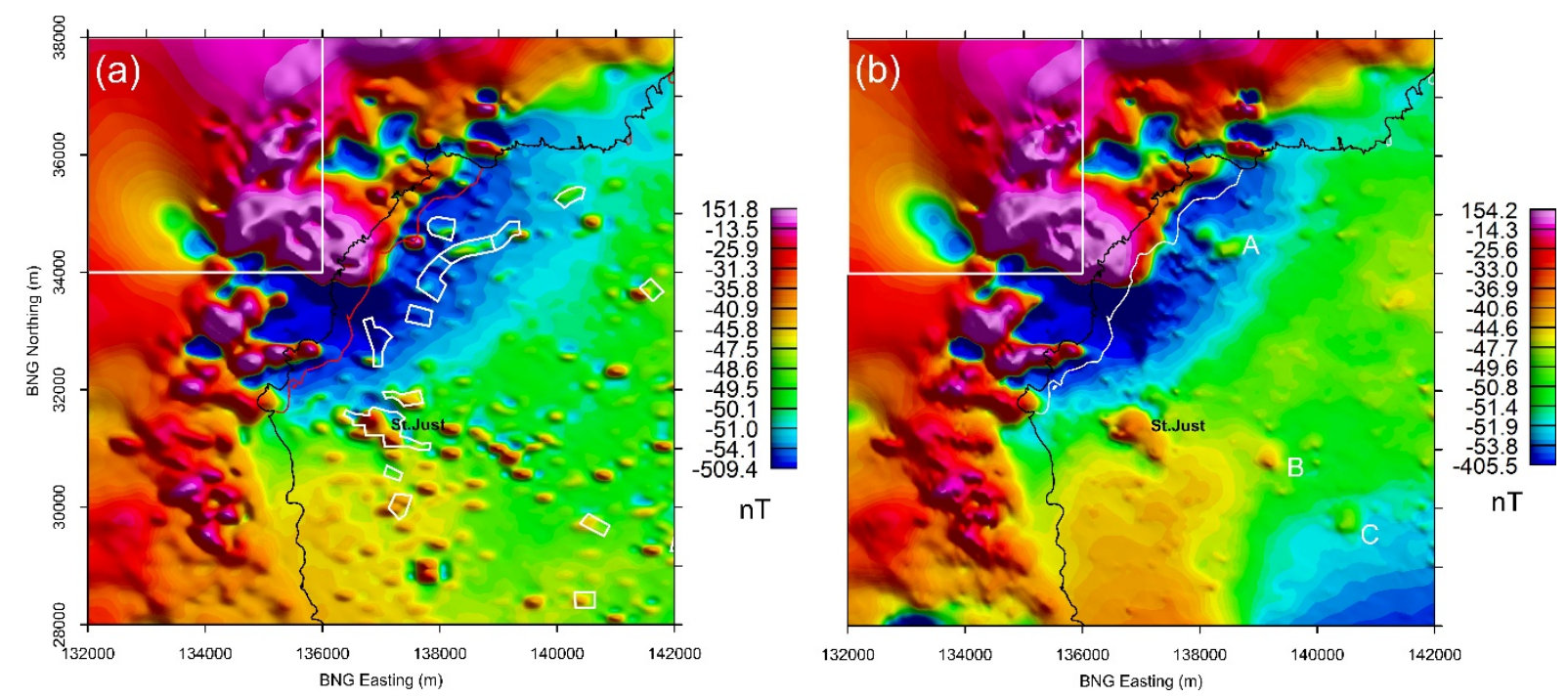

Figure 7. Study Area 2, $10 \times 10 \mathrm{~km}$. (a) TMI-RTP equal-area colour image of original data. White polygons denote small urban areas from a geographical database. (b) TMI-RTP equal-area colour image of KS solution processed data. NW $4 \times 4$ km rectangle area is used in Figure 8.

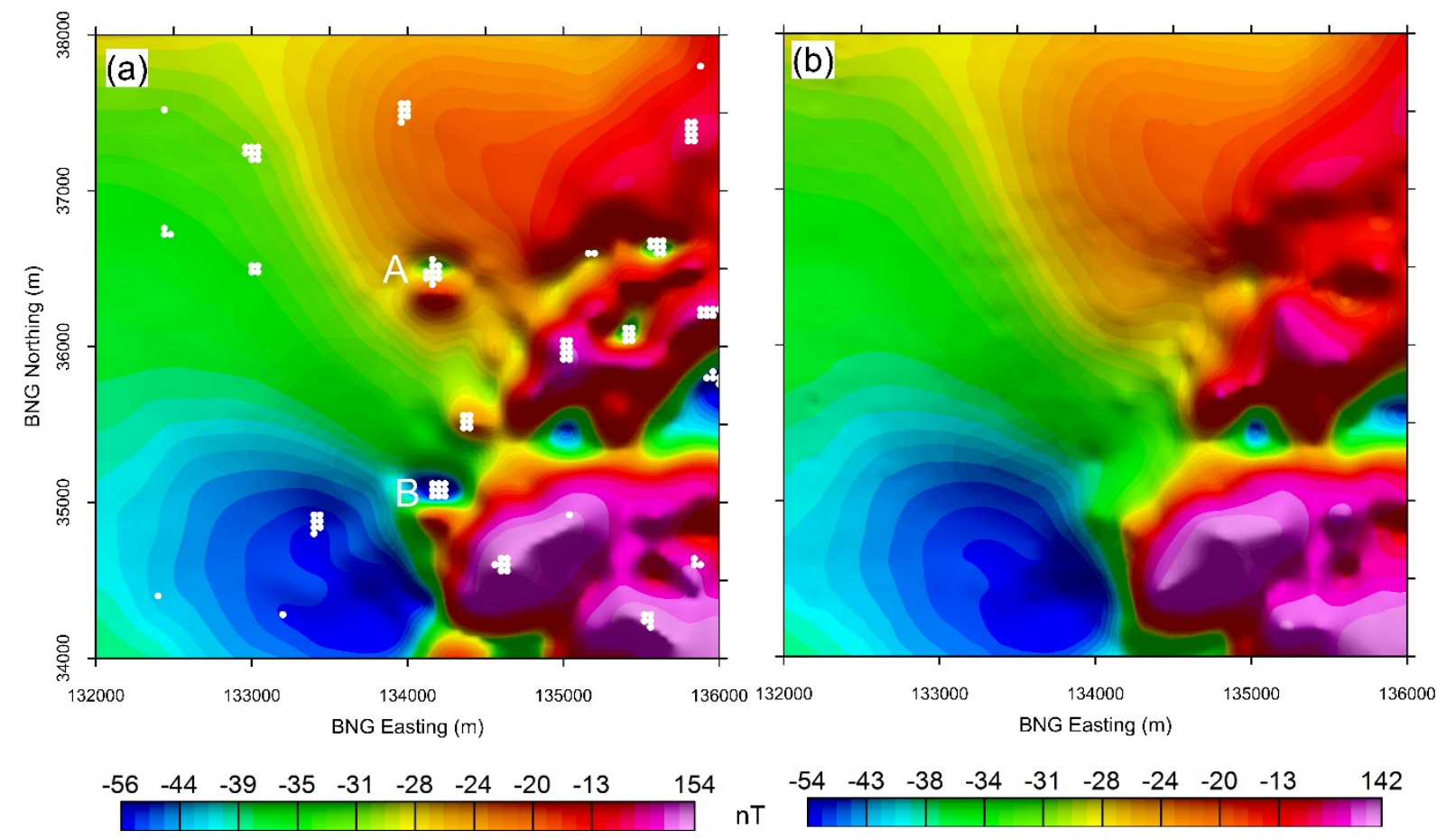

Figure 8. $4 \times 4 \mathrm{~km}$ offshore sub-area. (a) TMI-RTP equal-area colour image of original data. White symbols denote KS solution clusters. (b) TMI-RTP equal-area colour image of KS solution processed data. 

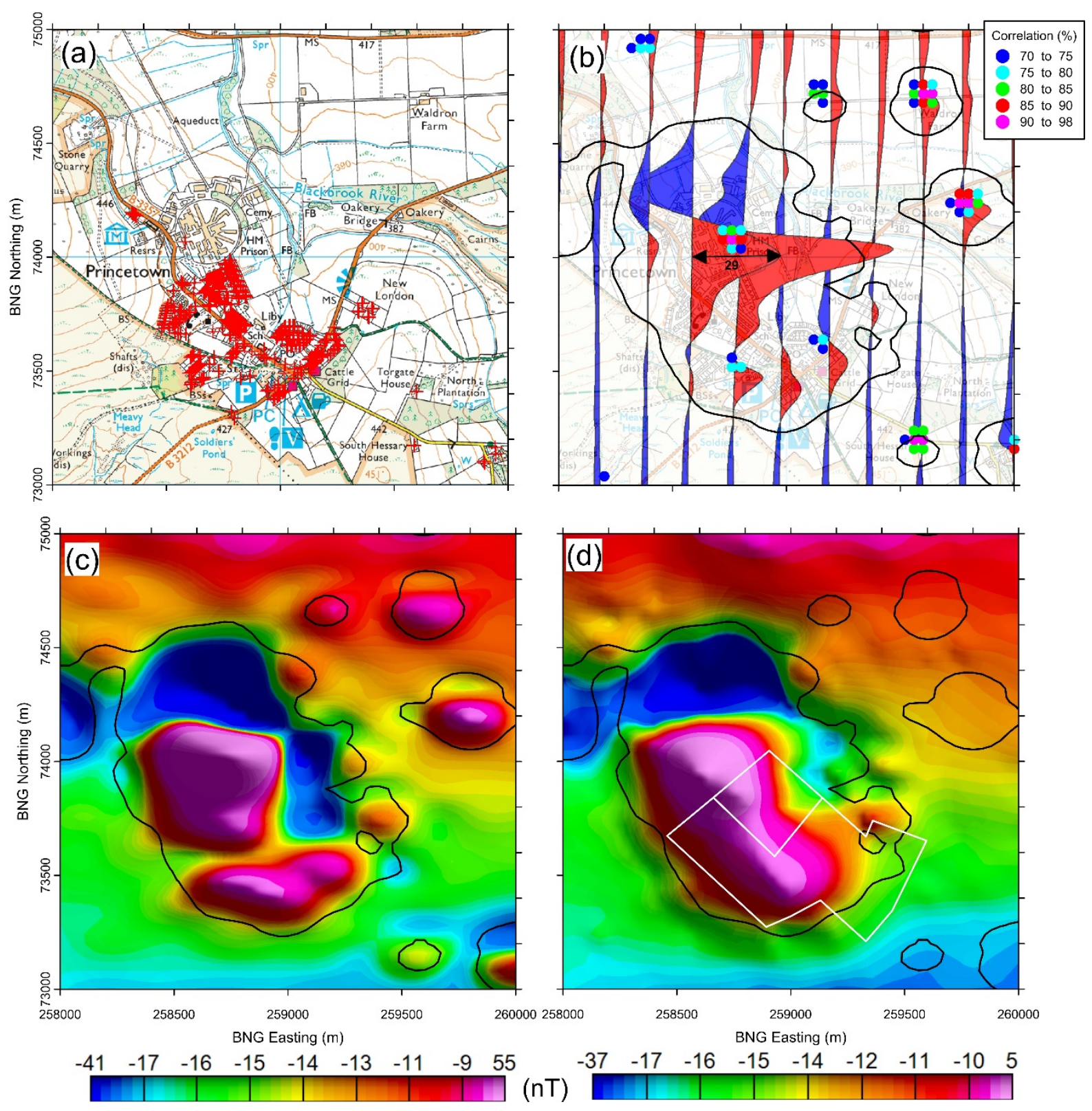

Figure 9. Study Area 3, $2 \times 2 \mathrm{~km}$. (a) Background 1:25k OS map with postcode symbols in red. (b) Wiggle-trace of TMI data along flight lines. Colour-coded KS solutions with correlation coefficients > $70 \%$, obtained using the TMI-AS data. Black contours denote values of TMI-AS $>0.03 \mathrm{nT} / \mathrm{m}$. (c) TMIRTP equal-area colour image of original data. (d) TMI-RTP equal-area colour image of KS solution processed data. White polygons denote small urban areas from a geographical database. 